\title{
INSTALASI PERMESINAN PADA KAPAL PSP 01
}

\section{(MACHINERY INSTALLATION ON PSP 01 BOAT)}

\author{
Anjaya Purwa Wiyastra ${ }^{2}$, Mulyono S. Baskoro² dan Fis Purwangka ${ }^{12}$ \\ ${ }^{1}$ Corresponding author \\ ${ }^{2}$ Departemen Pemanfaatan Sumberdaya Perikanan, FPIK-IPB \\ E-mail : fis_tli@yahoo.com
}

\begin{abstract}
PSP 01 boat is an accustomed boat and also fishing vessels that owned by the Department of Fisheries Resource Utilization (PSP), Faculty of Fisheries and Marine Sciences (FPIK), IPB. These ships use an inboard propulsion four stroke diesel engine from Mitsubishi Canter truck with type 4D30-C. This study aims to describe the modifications to the installation of ship machinery at the PSP 01 boat and describe the suitability of its machinery installation guidelines refer to the FAO in 2009 on the Safety Guide for Small Fishing Boats. These study approach by using case study method in which observation and data collection that includes modifications to the installation of ship machinery PSP 01 and compliance with the FAO guidelines on Safety Guide for Small Fishing Boats. The results obtained that the PSP 01 engine already modified on the ignition system, fuel system, lubrication system, transmission system, and engine cooling system. Based on FAO guidelines in 2009 on the Safety Guide for Small Fishing boats, installation of machinery on PSP 01 boat in bilge pump fullfilled $58.33 \%$, fuel system fulfilled $52.63 \%$, the combustion gas exhaust system met $33.33 \%$, the engine room vents are met $0 \%$, range $85.71 \%$ met the electrical installation, battery installation are met 100\%, daily checks before turning on the engine are met $75 \%$, daily checks after turning on the engine are met 100\%, the examination of every fourteen days are met $20 \%$, and the examination of every $100-150$ hours of engine operation are fulfilled 0\%. Based on FAO guidelines in 2009 on the Safety Guide for Small Fishing Boats, installation of Machinery on PSP 01 Boat on a whole scale are fulfilled 47,65\%.
\end{abstract}

Keywords: PSP 01 ship, installation of machinery, safety guide for small fishing boats

\begin{abstract}
ABSTRAK
Kapal PSP 01 merupakan kapal latih sekaligus kapal penangkap ikan yang dimiliki oleh Departemen Pemanfaatan Sumberdaya Perikanan (PSP), Fakultas Perikanan dan Ilmu Kelautan (FPIK), IPB. Kapal ini menggunakan tenaga penggerak inboard engine berjenis diesel empat langkah yang berasal dari truk Mitsubishi Canter dengan tipe 4D30-C. Penelitian ini bertujuan untuk mendeskripsikan modifikasi instalasi permesinan di Kapal PSP 01 dan mendeskripsikan kesesuaian instalasi permesinannya mengacu pada pedoman FAO tahun 2009 tentang Safety Guide for Small Fishing Boats. Pendekatan dilakukan dengan menggunakan metode studi kasus dimana dilakukan pengamatan dan pengumpulan data yang meliputi modifikasi pada instalasi permesinan Kapal PSP 01 serta kesesuaiannya terhadap pedoman FAO tentang safety guide for small fishing boats. Hasil penelitian didapat bahwa mesin kapal PSP 01 dimodifikasi pada bagian sistem penyalaan, sistem bahan bakar, sistem pelumasan, sistem transmisi, dan sistem pendingin mesin. Berdasarkan pedoman FAO tahun 2009 tentang Safety Guide for Small Fishing boats, instalasi permesinan Kapal PSP 01 dalam hal sistem pompa lambung terpenuhi $58,33 \%$, sistem bahan bakar terpenuhi 52,63\%, sistem pembuangan gas pembakaran terpenuhi 33.33\%, ventilasi kamar mesin terpenuhi $0 \%$, rangkaian instalasi kelistrikan terpenuhi 85,71\%, instalasi baterai terpenuhi $100 \%$, pemeriksaan harian sebelum menyalakan mesin terpenuhi $75 \%$, pemeriksaan harian setelah menyalakan mesin terpenuhi $100 \%$, pemeriksaan tiap empat belas hari terpenuhi sebesar $20 \%$, dan pemeriksaan tiap 100-150 jam setelah mesin beroperasi terpenuhi sebesar $0 \%$.
\end{abstract}

Kata Kunci : Kapal PSP 01, Instalasi permesinan, safety guide for small fishing boats

\section{PENDAHULUAN}

Kapal PSP 01 merupakan kapal latih sekaligus kapal penangkap ikan yang dimiliki oleh Departemen Pemanfaatan Sumberdaya Perikanan (PSP), Fakultas Perikanan dan Ilmu Kelautan (FPIK) IPB. Kapal tersebut diperuntukkan sebagai kapal latih bagi mahasiswa Departemen PSP pada khususnya dan mahasiswa FPIK pada umumnya. Kapal PSP 01 juga digunakan untuk aktivitas penangkapan ikan. Alat tangkap utama yang dioperasikan di atas kapal tersebut adalah tuna handline dan beroperasi di sekitar rumpon yang terletak tidak jauh dari Teluk Palabuhanratu.

Mesin pada Kapal PSP 01 bertipe inboard engine yang menggunakan mesin diesel. Mesin diesel yang digunakan bertipe 4D30-C yang berasal dari truk Mitsubishi Canter asal 
Singapura. Alasan penggunaan mesin truk pada kapal PSP 01 adalah harga mesin yang lebih terjangkau dibanding menggunakan marine engine, kemudahan perawatan mesin dikerenakan konstruksinya yang lebih sederhana, kemudahan mendapatkan suku cadang mesin jika terjadi kerusakan, dan kemudahan memodifikasi sistem transmisinya dengan transfer case tipe marine gearbox yang umum tersedia di pasaran.

FAO (Food and Agriculture Organization) sebagai salah satu organisasi yang bernaung dibawah PBB, pada tahun 2009 mengeluarkan pedoman keselamatan bagi kapal perikanan berukuran kecil kecil (small scale fishing boats). Kapal perikanan berukuran kecil yang dimaksud FAO disini adalah kapal yang memiliki panjang total (LOA) tidak melebihi 24 meter, baik kapal berbahan kayu atau FRP (fiber reinforce plastic), berjenis mesin inboard engine maupun outboard engine, maupun kapal yang memiliki atap atau tak beratap. FAO membuat acuan tersebut bagi negara berkembang yang berada di Asia dan Afrika. Pedoman keselamatan yang dibuat salah satunya berisi mengenai instalasi sistem permesinan pada kapal. Instalasi tersebut meliputi sistem pompa lambung kapal, sistem bahan bakar, sistem kelistrikan, sistem pembuangan gas pembakaran, ventilasi kamar mesin, hingga perawatan pada mesin.

Instalasi permesinan yang baik pada sebuah kapal yang bukan menggunakan marine engine mutlak dilakukan agar kapal beropersi maksimal dan dapat meningkatkan optimasi penangkapan di perairan. Acuan dari Safety Guide for Small Fishing Boats yang dikeluarkan FAO menjabarkan dengan rinci instalasi permesinan yang baik agar kapal beroperasi dengan maksimal tanpa melupakan keselamatan.

Penelitian ini bertujuan untuk : (1) Mendeskripsikan modifikasi instalasi permesinan di Kapal PSP 01; (2) Mendeskripsikan kesesuaian instalasi permesinan di Kapal PSP 01 mengacu pada ketetapan FAO 2009 tentang safety guide for small fishing boats.

\section{METODOLOGI}

\subsection{Waktu dan Tempat Penelitian}

Pengambilan data di lapangan dilakukan selama satu minggu dari tanggal 27 Juni hingga 3 Juli 2011. Kapal yang diteliti adalah KM PSP 01 milik Departemen Pemanfaatan Sumberdaya Perikanan (PSP), Fakultas Perikanan dan Ilmu Kelautan, Institut Pertanian Bogor yang berada di PPN Palabuhanratu, Jawa Barat.

\subsection{Alat dan Bahan}

Alat dan bahan yang digunakan dalam penelitian ini adalah sebagai berikut :

1) Kapal PSP 01

Spesifikasi Kapal PSP 01dalam penelitian ini :

Nama : KM. PSP 01

Pemilik : Departemen Pemanfaatan Sumberdaya Perikanan, Fakultas Perikanan dan Ilmu Kelautan, Institut Pertanian Bogor

Panjang kapal seluruhnya (LOA)

: 14,30 meter

Lebar (Breadth)

$$
\text { : 3,12 meter }
$$

Dalam kapal (Depth)

$$
\text { : } 1,20 \text { meter }
$$

Isi kotor (Gross Tonnage)

$$
\text { : 9,5 GT }
$$

Mesin penggerak

$$
\text { : Mitsubishi 4D30-C } 54 \text { PS }
$$

2) Kamera digital untuk mendokumentasikan seluruh kegiatan penelitian

3) Jangka sorong untuk mengukur beberapa bagian dari instalasi permesinan Kapal PSP 01 yang seperti mengukur diameter dan tebal bahan.

4) Penggaris mistar untuk mengukur beberapa bagian dari instalasi Kapal PSP 01 yang tidak bisa diukur jika menggunakan jangka sorong.

5) Meteran jahit untuk mengukur beberapa bagian dari instalasi permesinan kapal PSP 01 yang memerlukan kelenturan alat ukur.

6) Alat tulis dan data sheet untuk mencatat instalasi permesinan di Kapal PSP 01 yang sesuai maupun tidak sesuai dengan pedoman safety guide for small fishing boats yang dikeluarkan oleh FAO tahun 2009. 


\subsection{Metode Penelitian}

Metode yang digunakan dalam penelitian ini adalah metode studi kasus. Peneliti melakukan pengamatan langsung pada Kapal PSP 01 yang berlabuh di PPN Palabuhanratu, Jawa Barat. Dalam kegiatan tersebut dilakukan pengamatan dan pengumpulan data yang meliputi modifikasi yang dilakukan terhadap instalasi permesinan Kapal PSP 01 serta kesesuaiannya dengan pedoman FAO tentang Safety Guide for Small Fishing Boats.

Instalasi permesinan yang menjadi perhatian pada Kapal PSP 01 adalah sistem penyalaan dan kelistrikan, sistem bahan bakar, sistem transmisi, sistem pelumasan, sistem pendinginan mesin, sistem pompa lambung, dan sistem pembuangan gas pembakaran. Adapun hal di luar instalasi permesinan yang turut pula menjadi perhatian dikarenakan peranannya yang berkaitan dengan instalasi permesinan yaitu perawatan mesin dan ventilasi kamar mesin.

\subsection{Analisis Data}

Analisis data yang digunakan dalam penelitian ini adalah metode skoring. Skoring tersebut dilakukan terhadap instalasi permesinan pada Kapal PSP 01 yang berkaitan dengan pedoman dari FAO.

Nilai skoring $=\frac{\text { Total kriteria pada ma } \sin g-\text { ma } \sin g \text { aspek }}{\text { Total nilai kriteria keseluruhan }} \times 100 \%$

Persentase nilai skoring diperoleh dengan membandingkan total kriteria pada masing-masing aspek dengan total nilai kriteria keseluruhan dan dikalikan seratus persen. Kriteria dan aspek yang dimaksud dalam hal ini adalah butirbutir pedoman dari FAO tentang safety guide for small fishing boats yang berkaitan dengan instalasi permesinan Kapal PSP 01. Kriteria yang ada pada masing-masing aspek adalah:

1. Sistem pompa pada lambung kapal

2. Sistem bahan bakar

3. Sistem kelistrikan

4. Sistem pembuangan gas pembakaran

5. Perawatan mesin

6. Ventilasi kamar mesin

\section{HASIL DAN PEMBAHASAN}

\subsection{Sistem Kerja Mesin Diesel}

\subsubsection{Mesin diesel}

Berdasarkan klasifikasi motor diesel yang dijabarkan oleh Soenarta dan Furuhama (1985), mesin Mitsubishi 4D30-C yang digunakan oleh Kapal PSP 01 merupakan motor diesel empat langkah, berpendingin air, memiliki empat buah silinder bersusunan bentuk baris dan berkedudukan vertikal, serta memiliki tipe pembakaran kamar terpisah, yaitu jenis kamar mula dimana terdapat ruang bakar tambahan di atas ruang bakar utama di kepala silinder.

Mesin Mitsubishi 4D30-C memiliki empat langkah kerja dalam satu siklusnya yaitu, langkah isap (intake), langkah tekan (compression), langkah tenaga (power), dan langkah buang (exhaust). Keempat langkah kerja ini terjadi dalam dua kali putaran poros engkol.

\subsubsection{Sistem penyalaan}

Mesin 4D30-C pada Kapal PSP 01 menggunakan sistem penyalaan secara elektrik. Cara kerjanya adalah arus listrik yang dihasilkan accu menyebabkan dinamo starter berputar dan torsi yang dihasilkannya memutar poros engkol (crankshaft). Dinamo starter yang menempel pada bagian kiri mesin merupakan pembawaan mesin dan memakai sistem gear untuk memutar poros engkol. Putaran pada poros engkol itulah yang menyebabkan mesin bekerja secara berkelanjutan menurut siklusnya.

Pada kondisi awal truk Canter hanya mengunakan dua buah accu sebagai penunjang sistem penyalaannya, kemudian dimodifikasi dengan menggunakan 4 buah accu yang masingmasing berkapasitas 120 Ah. Dua buah accu untuk menyuplai listrik bagi dinamo starter dan dua buah lainnya untuk menyuplai listrik bagi lampu kabin, lampu ruang mesin, dan GPS. Sistem pengisian accu memakai dynamo charge atau alternator. Alternator ini terletak pada bagian depan mesin dan dihubungkan dengan sabuk (belt).

\subsubsection{Sistem bahan bakar}

Tangki bahan bakar pada Kapal PSP 01 terbuat dari fiberglass dan berbentuk balok. Dimensi panjang $\mathrm{x}$ lebar dan tingginya berukuran $105 \mathrm{~cm} \mathrm{x}$ 
$70 \mathrm{~cm} \mathrm{x} 61 \mathrm{~cm}$ dan didapat volumenya kurang lebih sebesar 448,35 liter. Tangki tersebut tersebut terletak pada bagian bawah dek sebelah buritan.

Bahan bakar yang akan melalui pompa bahan bakar untuk dikirim menuju injektor sebelumnya harus melewati filter bahan bakar yang berjumlah dua buah. Penggunaan filter ganda tersebut agar bahan bakar yang dikirim lebih bersih dari kotoran sehingga tidak menyumbat injektor.

Pompa bahan bakar pada mesin ini berjumlah dua buah, yaitu pompa transfer untuk memindahkan bahan bakar dari tangki menuju pompa injeksi, dan pompa injeksi untuk menyalurkan bahan bakar menuju injektor. Pada saluran setelah pompa injektor, terdapat pipa pembalik yang berfungsi mengembalikan bahan bakar yang berlebihan menuju kembali ke tangki bahan bakar.

\subsubsection{Sistem Transmisi}

Sistem transmisi pada Kapal PSP 01 dimodifikasi menggunakan transfer case tipe marine gear box buatan Hangzhou Foda Gear Box Group Co.LTD. Transfer case tersebut memiliki reduksi 3:1 yang berarti tiga kali putaran mesin menghasilkan satu kali putaran poros propeller.

\subsubsection{Sistem pelumasan}

Sistem pelumasan pada Kapal PSP 01 terdiri dari dua macam, yaitu pelumasan untuk mesin 4D30-C dan pelumasan untuk transmisi. Pelumasan pada mesin 4D30-C telah mengalami modifikasi agar ketahanannya terjaga. Mesin tersebut didesain untuk medan darat dan ketika diubah menjadi mesin kapal sangat mungkin menghasilkan panas lebih besar karena beroperasi pada putaran mesin konstan dalam jangka waktu lebih lama. Mesin tersebut dimodifikasi pada bagian karter atau penampung oli menjadi lebih besar sehingga dapat menampung pelumas sebanyak dua belas liter. Pembesaran kapasitas pelumas dimaksudkan agar pelumas mampu maksimal menyerap panas mesin yang berlebih.

Transfer case pada sistem transmisi Kapal PSP 01 menggunakan pelumas sebanyak tiga liter. Baik pelumasan mesin maupun pelumasan transfer case menggunakan pelumas dengan viskositas (kekentalan) SAE 40.

\subsubsection{Sistem pendinginan}

Sistem pendinginan pada mesin 4D30-C menggunakan radiator. Sistem ini memungkinkan suhu mesin tetap stabil dan suara mesin lebih halus. Pada Mitsubishi Canter, air dalam radiator didinginkan oleh hembusan angin yang datang ketika truk berjalan dan oleh hembusan kipas. Agar sistem pendinginan tetap optimal ketika mesin tersebut dioperasikan di perairan, maka hembusan angin digantikan oleh air laut. Kotak radiator tersebut dimodifikasi agar dapat menampung air tawar dan air laut namun tetap tidak tercampur agar mesin tidak mengalami korosi. Air laut berasal dari air yang menggenangi bawah kamar mesin dan dipompakan ke radiator agar mendinginkan air tawar. Air laut yang telah mendinginkan air tawar akan menjadi hangat karena perpindahan panas dari air tawar tersebut dan akhirnya dibuang lewat sisi kiri dan kanan kapal.

\subsection{Acuan Instalasi Permesinan Berdasarkan Ketetapan FAO 2009 tentang Safety Guide For Small Fishing Boats}

\subsubsection{Sistem pompa pada lambung kapal}

Persentase instalasi sistem pompa lambung pada Kapal PSP 01 yang memenuhi pedoman dari Safety Guide for Small Fishing Boats yang dikeluarkan FAO sebesar 58,33\%. Instalasi yang memenuhi syarat adalah:

1) Kapal PSP 01 memiliki dua buah pompa lambung yang digerakkan secara otomatis (dengan mesin) dan manual.

2) Terdapat sekat yang rapat antara ruang mesin dan palka.

3) Terdapat filter yang terbuat dari pipa PVC berlubang untuk menyaring air yang akan menuju pompa lambung.

4) Pipa yang menuju pompa lambung harus tahan oli, kuat terhadap hisapan, dan diameternya minimal seukuran lubang masuk (inlet).

5) Debit pada pompa lambung pada Kapal PSP 01, baik pompa otomatis maupun pompa manual lebih dari 140 liter/menit.

6) Jalur outlet pada pompa lambung Kapal PSP 01 berjarak lebih dari 350 
mm, sehingga boleh tidak menggunakan katup pada jalur outlet tersebut.

7) Pompa lambung yang digerakkan secara manual terpasang tetap di geladak dan pompanya berupa piston (piston pump).

Adapun persentase instalasi sistem pompa lambung pada Kapal PSP 01 yang tidak memenuhi pedoman dari Safety Guide for Small Fishing Boats yang dikeluarkan FAO sebesar 41,67\%. Instalasi yang tidak memenuhi syarat adalah:

1) Pompa lambung pada Kapal PSP 01 hanya menghisap air yang menggenangi ruang mesin, dan tidak menghisap air di palka.

2) Terdapat saringan pompa namun tidak tersambung dengan pipa fleksibel, melainkan tersambung dengan pipa PVC sehingga sulit dibongkar dan dibersihkan.

3) Tidak terdapat katup tiga arah pada pengatur pompa lambung.

4) Pompa tidak menggunakan impeller berbahan karet.

5) Kapal tidak memiliki alarm untuk menunjukkan ketinggian air yang menggenangi kamar mesin.

\subsubsection{Sistem bahan bakar}

Persentase instalasi sistem bahan bakar pada Kapal PSP 01 yang memenuhi acuan dari Safety Guide for Small Fishing Boats yang dikeluarkan FAO sebesar 52,63\%. Instalasi yang memenuhi syarat adalah:

1) Tangki bahan bakar pada Kapal PSP 01 ukuran panjangnya kurang dari 1,2 m, yaitu 1,05 m sehingga boleh tidak memakai sekat pada tangkinya.

2) Lubang pengisian bahan bakar memakai selang karet pendek yang lentur dan tahan terhadap bahan bakar diesel.

3) Sebelum filter bahan bakar pertama, terdapat pipa tembaga tanpa sambungan dan kuat dengan ketebalan dinding minimal 0,8 $\mathrm{mm}$ serta terpasang tetap dengan klem pengunci.

4) Kapal PSP 01 tidak memiliki dua buah tangki bahan bakar sehingga boleh tidak memakai katup tiga jalur pada saluran bahan bakar sebelum filter pertama.

5) Filter bahan bakar pertama tidak menempel pada mesin sehingga terbebas dari getaran mesin. oleh karena itu, selang bahan bakar yang terletak di antara filter bahan bakar pertama dengan pompa transfer boleh tidak terbuat dari anyaman logam.

6) Terdapat filter bahan bakar utama dan pemisah air (water separator) yang letaknya sebelum pompa bahan bakar.

7) Terdapat pompa bahan bakar yang mengalirkan bahan bakar dari tangki menuju pompa injektor.

8) Terdapat filter bahan bakar tambahan yang memastikan bahan bakar tersaring sempurna sebelum menuju pompa injektor.

9) Terdapat pompa injektor yang mengalirkan bahan bakar menuju injektor.

10) Terdapat injektor yang berfungsi menyemprotkan bahan bakar dalam bentuk kabut halus menuju ruang bakar.

Adapun persentase instalasi sistem bahan bakar pada Kapal PSP 01 yang tidak memenuhi pedoman dari Safety Guide for Small Fishing Boats yang dikeluarkan FAO sebesar 47,37\%. Instalasi yang tidak memenuhi syarat adalah:

1) Tangki bahan bakar tidak terbuat dari pelat baja yang dilas, melainkan terbuat dari fiberglass.

2) Tidak terdapat lubang untuk membersihkan tangki bahan bakar. Lubang tersebut seharusnya terdapat pada samping tangki bahan bakar.

3) Lubang untuk pengisian bahan bakar pada Kapal PSP 01 tidak memiliki sumbat berbentuk sekrup dan lubang tersebut tidak menonjol diatas dek.

4) Tidak terdapat penjepit berbahan stainless steel pada lubang pengisian tangki bahan bakar.

5) Tidak terdapat pipa ventilasi pada tangki bahan bakar yang terpisah dari lubang pengisian bahan bakar.

6) Tanda batas ketinggian bahan bakar tidak memiliki katup yang dapat menutup sendiri pada bagian bawahnya.

7) Tidak terdapat tempat berkumpulnya bahan bakar berikut katup pengurasnya pada bagian dasar tangki bahan bakar.

8) Tidak terdapat katup penghenti bahan bakar untuk menghentikan aliran bahan bakar secara darurat ketika terjadi bahaya kebakaran. 
9) Pipa saluran pembalik bahan bakar tidak seluruhnya terbuat dari tembaga tanpa sambungan dan kuat. Pipa tersebut pada beberapa bagian disambung dengan selang plastik.

\subsubsection{Sistem kelistrikan}

\section{Rangkaian instalasi kelistrikan}

Persentase instalasi sistem rangkaian instalasi kelistrikan pada Kapal PSP 01 yang memenuhi pedoman dari Safety Guide for Small Fishing Boats yang dikeluarkan FAO sebesar $85,71 \%$. Instalasi yang memenuhi syarat adalah:

1) Baterai yang digunakan untuk menyalakan mesin terpisah dari baterai yang digunakan untuk keperluan lainnya.

2) Terdapat dua buah kabel dengan dua kutub saklar. Selain itu saklar utama terletak sedekat mungkin dengan baterai.

3) Baterai diletakkan dekat dengan motor starter untuk meminimalkan kehilangan arus listrik akibat panjangnya kabel.

4) Kabel menggunakan ukuran yang telah ditentukan olah pabrikan mesin.

5) Terdapat papan saklar utama. Selain itu, lampu navigasi utama menggunakan sekering yang terpisah.

6) Semua saklar dan sekering ditandai dengan jelas.

Adapun persentase instalasi sistem rangkaian instalasi kelistrikan pada Kapal PSP 01 yang tidak memenuhi pedoman dari Safety Guide for Small Fishing Boats yang dikeluarkan FAO sebesar $14,29 \%$. Instalasi yang tidak memenuhi syarat adalah:

- Semua titik kontak pemakaian tidak dilepaskan ketika saklar utama dalam kondisi "off".

\section{Baterai}

Persentase instalasi baterai pada Kapal PSP 01 yang memenuhi pedoman dari Safety Guide for Small Fishing Boats yang dikeluarkan FAO sebesar 100\%. Instalasi yang memenuhi syarat adalah:

1) Baterai untuk penyalaan mesin memakai baterai otomotif dan memiliki lebih dari $50 \%$ dari yang diperlukan baterai untuk penyalaan mesin.

2) Untuk penggunaan umum, Kapal PSP 01 menggunakan baterai dengan siklus mendalam (deep cycle battery). Siklus mendalam yang dimaksud adalah baterai yang memiliki siklus pengisian dan pengeluaran.

3) Terdapat instrumen pengukur tegangan untuk memastikan kerja baterai untuk keperluan lainnya mencukupi kebutuhan.

4) Baterai terkunci dengan kokoh di ruang mesin.

5) Pengisian tidak pernah melewati $5 \mathrm{~kW}$ sehingga baterai tidak harus diletakkan pada kotak khusus berventilasi.

\subsubsection{Sistem pembakaran}

\section{pembuangan gas}

Persentase instalasi sistem pembuangan gas pembakaran pada Kapal PSP 01 yang memenuhi pedoman dari Safety Guide for Small Fishing Boats yang dikeluarkan FAO sebesar 33,33\%. Instalasi yang memenuhi syarat adalah:

1) Terdapat pintu keluar untuk ujung pipa knalpot pada bagian paling atas dari rumah geladak.

2) Pipa knalpot beserta peredamnya (silencer) harus terbungkus dengan insulasi berbahan glasswool atau rockwool dan terlindungi dengan penutup yang sesuai.

3) Pipa knalpot yang panas memiliki celah dengan bagian kapal yang terbuat dari kayu sebesar minimal $100 \mathrm{~mm}$.

4) Diameter pipa knalpot pada bagian akhir besarnya minimal sama dengan manifold knalpot pada mesin agar tidak menghambat laju gas pembakaran yang dikeluarkan oleh mesin.

Adapun persentase instalasi sistem pembuangan gas pembakaran pada Kapal PSP 01 yang tidak memenuhi pedoman dari Safety Guide for Small Fishing Boats yang dikeluarkan FAO sebesar $66,73 \%$. Instalasi yang tidak memenuhi syarat adalah:

1) Jalur lubang pembuangan ke atas namun tidak melewati saluran ventilasi yang besar, karena tidak terdapat saluran ventilasi.

2) Sistem pembuangan gas pada Kapal PSP 01 mengalami kebocoran sehingga asap knalpot memenuhi ruang mesin.

3) Sambungan pipa knalpot tidak memakai sistem flens yang seharusnya dapat lebih mudah dibongkar untuk perawatan 
dibandingkan dengan sambungan sekrup.

4) Tidak terdapat bagian dari pipa knalpot yang berfungsi untuk mengumpulkan air yang terkondensasi.

5) Pipa knalpot pada Kapal PSP 01 tidak menggunakan pipa dengan tekukan yang landai.

6) Tidak terdapat baja yang fleksibel pada bagian bawah manifold knalpot yang seharusnya disuplai oleh pabrikan mesin.

7) Tidak terdapat sistem pengusir asap knalpot (exhaust air ejector) pada ujung pipa knalpot.

8) Pipa knalpot tidak menggunakan penyokong sehingga pipa knalpot tersebut membebani sambungan knalpot pada mesin (exhaust engine manifold).

\subsubsection{Perawatan mesin}

\section{Pemeriksaan harian} menyalakan mesin

Persentase pemeriksaan harian sebelum menyalakan mesin pada Kapal PSP 01 yang memenuhi pedoman dari Safety Guide for Small Fishing Boats yang dikeluarkan FAO sebesar 75\%. Pemeriksaan yang memenuhi syarat adalah:

1) Memeriksa ketinggian pelumas pada mesin.

2) Memeriksa ketinggian air pendingin.

3) Memeriksa ketersediaan bahan bakar.

Adapun persentase pemeriksaan harian sebelum menyalakan mesin pada Kapal PSP 01 yang tidak memenuhi pedoman dari Safety Guide for Small Fishing Boats yang dikeluarkan FAO sebesar 25\%. Pemeriksaan yang tidak memenuhi syarat adalah :

- Tidak terdapat ketersediaan gemuk otomatis untuk melumasi poros propeller.

\section{Pemeriksaan harian menyalakan mesin}

Persentase pemeriksaan harian setelah menyalakan mesin pada Kapal PSP 01 yang memenuhi pedoman dari Safety Guide for Small Fishing Boats yang dikeluarkan FAO sebesar 100\%. Pemeriksaan yang memenuhi syarat adalah:
1) Memastikan
air bersirkulasi.

2) Memeriksa pipa air pendingin, pipa knalpot, saluran bahan bakar, dan pipa oli terhadap kemungkinan kebocoran.

3) Memeriksa tekanan oli.

4) Memeriksa indikator pengisian baterai (accu).

\section{Pemeriksaan tiap empat belas hari}

Persentase pemeriksaan tiap empat belas hari pada Kapal PSP 01 yang memenuhi pedoman dari Safety Guide for Small Fishing Boats yang dikeluarkan FAO sebesar 20\%. Pemeriksaan yang memenuhi syarat adalah:

- Memeriksa ketinggian air accu. Tambahkan dengan air murni terdistilasi jika dibutuhkan.

Adapun persentase pemeriksaan tiap empat belas hari pada Kapal PSP 01 yang tidak memenuhi pedoman dari Safety Guide for Small Fishing Boats yang dikeluarkan FAO sebesar $80 \%$. Pemeriksaan yang tidak memenuhi syarat adalah:

1) Pemeriksaan ketegangan sabuk alternator tidak dilakukan.

2) Tidak melakukan pembuangan air dan kotoran yang berada dalam filter bahan bakar.

3) Tidak ada pemeriksaan kekencangan baut mesin dan baut propeller.

4) Tidak ada pemeriksaan pada paking mesin.

\section{Pemeriksaan tiap 100-150 jam mesin beroperasi}

Persentase pemeriksaan tiap 100150 jam mesin beroperasi pada Kapal PSP 01 yang memenuhi pedoman dari Safety Guide for Small Fishing Boats yang dikeluarkan FAO sebesar 0\%. Adapun persentasi pemeriksaan tiap 100-150 jam mesin beroperasi pada Kapal PSP 01 yang tidak memenuhi pedoman dari Safety Guide for Small Fishing Boats yang dikeluarkan FAO sebesar 100\%. Pemeriksaan yang tidak memenuhi syarat adalah:

1) Mengganti oli mesin diatas 100-150 jam mesin beroperasi.

2) Mengganti filter oli diatas 100-150 jam mesin beroperasi.

3) Mengganti oli transmisi diatas 100150 jam mesin beroperasi.

4) Tidak pernah melakukan penggantian filter bahan bakar. 


\subsubsection{Ventilasi kamar mesin}

Persentase instalasi ventilasi kamar mesin pada Kapal PSP 01 yang memenuhi pedoman dari Safety Guide for Small Fishing Boats yang dikeluarkan FAO sebesar $0 \%$. Adapun persentase instalasi ventilasi kamar mesin pada Kapal PSP 01 yang tidak memenuhi pedoman dari Safety Guide for Small Fishing Boats yang dikeluarkan FAO sebesar $100 \%$. Pemeriksaan yang tidak memenuhi syarat adalah:

1) Tidak terdapat saluran untuk membuang panas pada ruang mesin.

2) Pipa knalpot tidak diletakkan pada lubang ventilasi keluar tetapi menjulur keluar melalui lubang di atap.

3) Tidak terdapat saluran melintang yang bersekat - sekat yang berfungsi untuk memaksimalkan pengeluaran udara panas dari ruang mesin.

\section{KESIMPULAN DAN SARAN}

1) Modifikasi yang dilakukan pada mesin Kapal PSP 01 terletak pada sistem penyalaan yang menggunakan empat buah accu, sistem bahan bakar menggunakan bahan fiberglass untuk tangki bahan bakar, sistem pelumasan dimodifikasi pada bagian karter atau penampung oli yang diperbesar agar dapat menampung pelumas lebih banyak, Sistem transmisi menggunakan transfer case tipe marine gearbox, dan pada sistem pendinginan mesin modifikasi dilakukan pada bagian radiator.

2) Berdasarkan ketetapan FAO tahun 2009 tentang Safety Guide for Small Fishing Boats, instalasi permesinan:

(1) Pompa lambung terpenuhi $58,33 \%$,

(2) Instalasi sistem bahan bakar terpenuhi 52,63\%,

(3) Sistem pembuangan gas pembakaran terpenuhi 33,33\%,

(4) Ventilasi kamar tidak terpenuhi sama sekali $(0 \%)$,

(5) Pada sistem kelistrikan terdapat rangkaian instalasi kelistrikan terpenuhi $85,71 \%$ dan instalasi baterai terpenuhi seluruhnya $(100 \%)$,

(6) Pada perawatan mesin terdapat pemeriksaan harian sebelum menyalakan mesin terpenuhi $75 \%$, kemudian pemeriksaan harian setelah menyalakan mesin terpenuhi seluruhnya $(100 \%)$, pemeriksaan tiap empat belas hari sebesar $20 \%$, dan pemeriksaan tiap 100-150 jam mesin beroperasi tidak terpenuhi sama sekali $(0 \%)$.

(7) Kesesuaian instalasi permesinan Pada Kapal PSP 01 dengan pedoman FAO tahun 2009 tentang Safety Guide foe Small Fishing Boats secara keseluruhan sebesar $47,65 \%$.

(8) Adapun hal utama yang perlu diperhatikan dalam instalasi permesinan Kapal PSP 01 berdasar kesesuaiannya dengan pedoman FAO, yaitu instalasi ventilasi kamar mesin, sistem pembuangan gas pembakaran, dan perawatan mesin.

\subsection{Saran}

1) Perlu dilakukan penelitian serupa pada beberapa kapal ikan dengan ukuran yang sama pada lokasi lainnya.

2) Perlu dilakukan penelitian tentang modifikasi permesinan pada beberapa kapal ikan lainnya mengenai kesesuaiannya terhadap pedoman yang dikeluarkan oleh FAO tahun 2009 tentang Safety Guide for Small Fishing Boats.

\section{DAFTAR PUSTAKA}

Anonim. 2010. Diesel Cycle Operation. [terhubung tidak berkala]. www.kruse-ltc.com/diesel/ diesel_cycle.php. $\quad[10$ Oktober 2010].

Abidin, Z. 2006. Perbandingan Aspek Konsumsi Bahan Bakar Mesin Diesel Berbahan Bakar Dasar Solar dengan Penambahan Biodiesel Minyak Jelantah. Skripsi [tidak dipublikasikan]. Depok: Departemen Teknik Mesin. Fakultas Teknik. Universitas Indonesia.

Arismunandar, W. 1977. Penggerak Mula Motor Bakar Torak. Bandung: Institut Teknologi Bandung.

Echuzen, K. et al. 1987. Mesin Perkapalan I. Tokyo: Overseas Fishery Cooperation Foundation. 
Fyson, J. 1985. Design of Small Fishing Vessel. Rome: FAO of the United Nation.

Maleev, VL. 1995. Operasi dan Pemeliharaan Mesin Diesel. Bambang Priambodo, penerjemah. Jakarta: Penerbit Erlangga. Terjemahan dari: Diesel Engine Operation and Maintenance.

Muklis. 2004. Perubahan Kinerja Mesin Utama Kapal Motor Latih Stella Maris. Skripsi [tidak dipublikasikan]. Bogor: Fakultas Perikanan dan Ilmu Kelautan. Institut Pertanian Bogor.
Soenarta, N dan S. Furuhama. 1985. Motor Serba Guna. Jakarta: Pradnya Paramita.

Susanto, Adi. Evaluasi Desain dan Stabilitas Kapal Penangkap Ikan di Palabuhanratu (Studi Kasus Kapal PSP 01). Tesis [tidak dipublikasikan]. Bogor: Fakultas Perikanan dan Ilmu Kelautan. Institut Pertanian Bogor.

Guldbransen, $\varnothing$. 2009. Safety Guide for Small Fishing Boats. FAO/SIDA/IMO/BOBP-IGO:

Rome. 